\title{
Analysis of briquetting process of sewage sludge with coal to combustion process
}

\author{
Bogdan Kosturkiewicz ${ }^{1, a}$ and Andrzej Janewicz ${ }^{1}$ \\ ${ }^{1}$ AGH University of Science and Technology, Faculty of Mechanical and Robotics, al. Mickiewicza 30, 30-059 Cracow, Poland
}

\begin{abstract}
Energy recovery from sewage sludge can be achieved by several thermal technologies, but before those processes sewage sludge requires special pretreatment. The paper presents the investigation of the sewage sludge with coal briquettes as a fuel for combustion process. Research is conducted at Department of Manufacturing Systems and Department of Thermal Engineering and Environmental Protection, AGH University of Science and Technology to develop a technology of briquette preparation. The obtained results showed possibility of briquetting of municipal sewage sludge with coal in roll presses, equipped with asymmetric thickening gravity feed system. The following properties were determined for the obtained briquettes: density, drop strength and compressive strength. Based on physical and chemical analysis of prepared briquettes it was confirmed that briquettes have good fuel properties to combustion process. Thermal behaviour of studied sewage sludge and prepared mixture was investigated by thermogravimetric analysis (TG). For the thermo gravimetric analysis (TG) the samples were heated in an alumina crucible from an ambient temperature up to $1000{ }^{\circ} \mathrm{C}$ at a constant rates: $10{ }^{\circ} \mathrm{C} / \mathrm{min}, 40{ }^{\circ} \mathrm{C} / \mathrm{min}$ and $100{ }^{\circ} \mathrm{C} / \mathrm{min}$ in a $40 \mathrm{ml} / \mathrm{min}$ flow of air.
\end{abstract}

\section{Introduction}

Article 14 of the Council Directive of 21 May 1991 regarding municipal sewage sludge obliges members of the EU to re-use the waste whenever it is appropriate. According to Statistical Yearbook of the Republic of Poland [1], around 85 thousand tons of dry mass of communal sewage sludge is being thermally converted. According to National plan of operation in range of energy from renewable sources [2], in 2020 over 400 thousand tons (around $57 \%$ of the waste) will be converted. In order to achieve such growth, development of new technologies regarding thermal converting waste will be necessary. For several years in Department of Manufacturing Systems, AGH University of Science and Technology, Krakow, research in order to develop new technologies in binding municipal sewage sludge [3-4]. Results confirmed possibility of obtaining briquettes from wastes using roll presses, which are characterised by compressive strength, allowing transporting the raw material and later utilising it in stoker-fired boilers installed in incineration plants. Calorific value of briquetting sewer sludge equalled around $8.7 \mathrm{MJ} / \mathrm{kg}$. Analysis of literature regarding this problem [5] suggests that even though there is no problem in combustion of such sewage sludge in thermal municipal plants (minimal calorific value of wastes allowing autothermal combustion on stoker equals $5800 \mathrm{~kJ} / \mathrm{kg}$ [6]), calorific value of produced briquette is too low for Polish cement plants. Their technicians claim that calorific value of waste fuel (of which energy is effectively used in process of clinker production) cannot be lower than $12 \mathrm{MJ} / \mathrm{kg}$ for solid fuel. Therefore, for example, Polish cement plants demand that minimal average weekly calorific value of sludge should equal $14 \mathrm{MJ} / \mathrm{kg}$ and average daily $11,7 \mathrm{MJ} / \mathrm{kg}$. Combustion of sewage sludge in cement industry is effective way for thermal utilization of sewage sludge as well as can reduce the consumption of coal. In order to increase calorific value of alternative fuel, the briquettes of municipal sludge with addition of coal and burnt lime were made. Next, the combustion process with thermal analysis (TA) of obtained briquettes was examined. The advantages of thermogravimetric analysis are its rapid assessment of the fuel value, the temperatures at which combustion starts and ends, and other characteristics, such as the maximum reactivity temperature, amount of ash and total combustion time. Thermal methods, such as Thermogravimetry (TG), Derivative Thermogravimetric Analysis (DTG) and Differential Thermal Analysis (DTA) have been used to study a variety of areas of combustion. Thermal analysis determines a set of methods for studying the selected physical properties of a substance under the influence of temperature or atmosphere [7-10]. As can be observed from the literature, the combustion and pyrolysis processes of sewage sludge from wastewater treatment plants and mixture of sewage sludge and coal are not explained sufficiently,

\footnotetext{
${ }^{a}$ Corresponding author: kostur@agh.edu.pl
} 
which could be due to the complex composition of sewage sludge and the diversity of the constituents.

The main aim of the study was to determine the possibility of briquetting mixture of municipal sewage sludge, burnt lime and coal. The obtained briquettes can be combustion in cement industry.

\section{Experimental}

Municipal sewage sludge from Municipal Water and Sewage Company in Poland was used in this study. The municipal sewage sludge from waste water treatment plant contains a lot of organic matter and some heavy metals and pathogenic organisms. The total content of organic matter is $43,7 \%$ (Table 1 ).

Table 1. Chemical analysis of municipal sewage sludge after dewatering process (Magdziarz A. et al.2011).

\begin{tabular}{|c|c|}
\hline Denotation & Value \\
\hline Organic matter, $\%$ d.m. & 43,7 \\
\hline Nitrogen, $\%$ d.m. & 2,9 \\
\hline Phosphorus, \% d.m. & 3,3 \\
\hline Calcium, \% d.m. & 2,4 \\
\hline Magnesium, \% d.m. & 0,33 \\
\hline Lead, $\mathrm{mg} / \mathrm{kg}$ d.m. & 75,6 \\
\hline Cadmium, mg/kg d.m. & 3,6 \\
\hline Mercury, mg/kg d.m. & 0,6 \\
\hline Nickel, mg/kg d.m. & 22,8 \\
\hline Zinc, mg/kg d.m. & 1183 \\
\hline Copper, mg/kg d.m. & 103 \\
\hline Chromium, mg/kg d.m. & 36,1 \\
\hline
\end{tabular}

Studied sludge contains a relatively large amount of organic matter, which suggests that it has got adequate fuel properties. Sewage sludge contains, of course, those components that are present in municipal waste, and thus trace metals whose levels may be higher than in the raw waste. Zinc is the most common of the trace elements. There are also copper and lead. It should be noted that in the investigated sludge the amount of harmful heavy metals $(\mathrm{Pb}, \mathrm{Cd}, \mathrm{Hg})$ is low. It is concluded that in terms of harmful substances per unit of energy, sludge is characterized by its fuel properties suggesting possibility of thermal utilization in industry.

The first step of sewage sludge briquetting process was homogenisation of the material composition. The samples were mixed in a mixer with a preheated water jacket. Taking into account the limitation of heat demand for sludge dewatering and appropriate biostabilization, for better uniting waste burnt lime was added. Mixing time was determined based on the study of amount of material moisture. The moisture value of tested sample was approximately $23.5 \%$. The percentage composition of studied mixture is presented in Table 2 .

Table 2. Percentage composition of prepared mixture for briquetting process.

\begin{tabular}{|c|c|c|c|}
\hline Mixture & $\begin{array}{c}\text { Sewage } \\
\text { sludge, } \%\end{array}$ & Burnt lime, \% & Coal, \% \\
\hline I & 45 & 5 & 50 \\
\hline II & 29.5 & 3.5 & 67 \\
\hline
\end{tabular}

Mineralogical characteristics and XRD spectrum of the sample of ash/slag from burning coal particular presented in Figure 1 and Table 3.

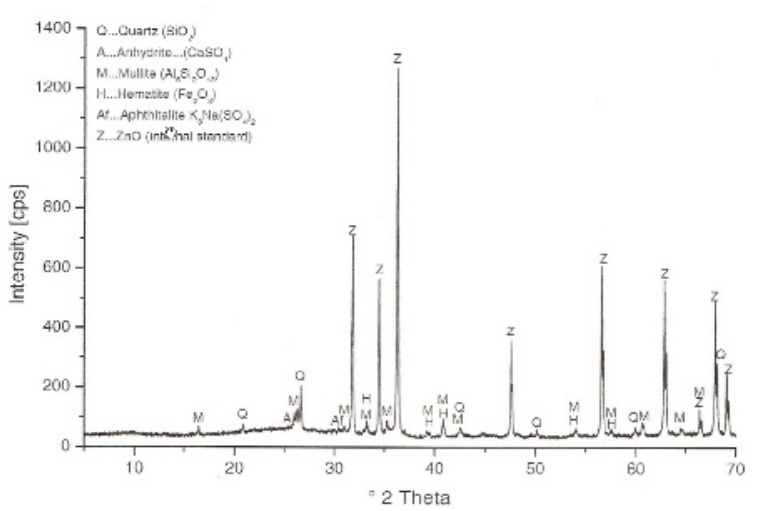

Figure 1. XRD spectrum of the sample of ash/slag from burning coal particular

Table 3. Results of the XRD analysis of the sample "Ash/slag" from burning coal particular

\begin{tabular}{|c|c|c|}
\hline Parameter & Unit & Results \\
\hline Amorphous & \% by mass & 77,8 \\
\hline Hematite & $\%$ by mass & $<0,5$ \\
\hline Mullite & $\%$ by mass & 17,1 \\
\hline Anhidrite & $\%$ by mass & $<0,5$ \\
\hline Aphthitalite & $\%$ by mass & $<0,5$ \\
\hline Quartz & $\%$ by mass & 4,2 \\
\hline
\end{tabular}


Prepared sample was fed into the hopper located above the zone of gravitational compaction of roller press LPW 450, which is equipped with forming rings for briquetting process without the parting plane in the shape of a saddle (Fig.2).

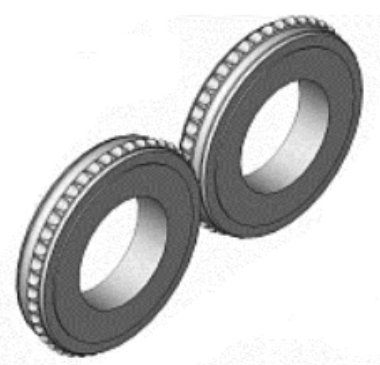

Figure 2. Asymmetrical layout compacting system of laboratory roll press LPW 450

It is known that the "saddle" shape of the working surface of the rollers allows high pressure units in the briquetting process. That kind of roller press is adequate for the uniting of difficult materials to briquetting. The amount of fine-grained material was $5 \div 7 \mathrm{~kg}$. The sample was united at $0,1 \div 0,4 \mathrm{~m} / \mathrm{s}$ of tangential velocity corresponding to rotational speed $4,25 \div 17,0 \mathrm{rpm}$. The initial value of the interspace between the rolls during briquetting process was $\mathrm{d} \sim 1,0$ $\mathrm{mm}$. The briquettes were obtained in shape presented in Figure 3.

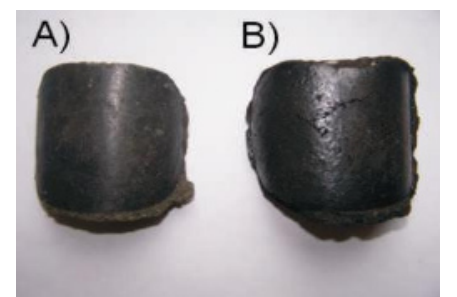

Figure 3. Photo of briquettes made of sewage sludge, lime and coal (A) mixture I, B) mixture II).

After leaving the cavities, the briquettes were stored in a container, from which samples were taken at random (in batches 10 pcs. each) in order to determine parameters characterising their mechanical properties. The following properties were determined for the obtained briquettes: the density $\left(\rho_{\mathrm{b}}\right)$, drop strength $\left(K_{168}\right)$ and compressive strength $\left(D_{168}\right)$.

Considering the loads character the briquettes are endangered to during their reloading, transportation and thermal management, it was decided that indexes that reflect their resistance to destruction at best shall be: compression strength and resistance to drop. Compressive strength tests of briquettes were performed at the measurement stand equipped with ZWICK 1120 press of pressure range $0 \div 2000 \mathrm{~N}$. The briquettes were pressed between two parallel planes at rate $v=0.001 \mathrm{~m} / \mathrm{s}$ and the direction of pressure were perpendicular to those planes. The strength tests were performed after $168 \mathrm{~h}$ seasoning in order to minimize the influence of atmospheric conditions (humidity, temperature) on the value of obtained results. Drops of briquettes in batches 10 each from height $2 \mathrm{~m}$ onto steel plate of thickness $60 \mathrm{~mm}$. This test was performed three times, each time sieving the broken mass at a sieve of mesh $18 \times 18 \mathrm{~mm}$. Size of sieve was determined to $2 / 3$ of average calculated from two maximum briquette dimensions measured in mutually perpendicular directions.

Thermogravimetric analysis was carried out using a Mettle Toledo TGA/SDTA 851 apparatus. The TGA instrument was calibrated with indium, zinc and aluminium. Its accuracy is equal to $10^{-6} \mathrm{~g}$. For the thermo gravimetric analysis (TG) the samples were placed in an alumina crucible. C.a. $15 \mathrm{mg}$ of sample was heated from an ambient temperature up to $1000{ }^{\circ} \mathrm{C}$ at a constant two rates: $10^{\circ} \mathrm{C} / \mathrm{min}, \quad 40{ }^{\circ} \mathrm{C} / \mathrm{min}$ and $100^{\circ} \mathrm{C} / \mathrm{min}$ in a $40 \mathrm{ml} / \mathrm{min}$ flow of air. The measurements for each sample have to be done under exactly the same condition including e.g. the range of temperatures, atmosphere, heating rate, etc. To determine the most repeatable and precise results. The TG curves represent the instantaneous weight percentage of the tested fuels in relation to the initial weight. The TG curves were used in order to assess the thermal characteristics of studied samples.

\section{Results and discussion}

Test results were processed statistically according to procedures specified for the estimation carried out by evaluation in points. Based on them authors described the influence of rotational speed on density and strength parameter of briquettes. Right after binding process they presented they showed a plastic material characteristics due to high moisture of samples of approximately $23.5 \%$. Plastic characteristic prevented determination of raw compressive strength of measured samples.

The obtained briquettes were characterized by a high drop of strength coefficient after the test had been made and after 168 hours had passed. Compressive strength of briquettes was very high (force needed for permanent decohesion exceeded 900 N) (Fig. 4).

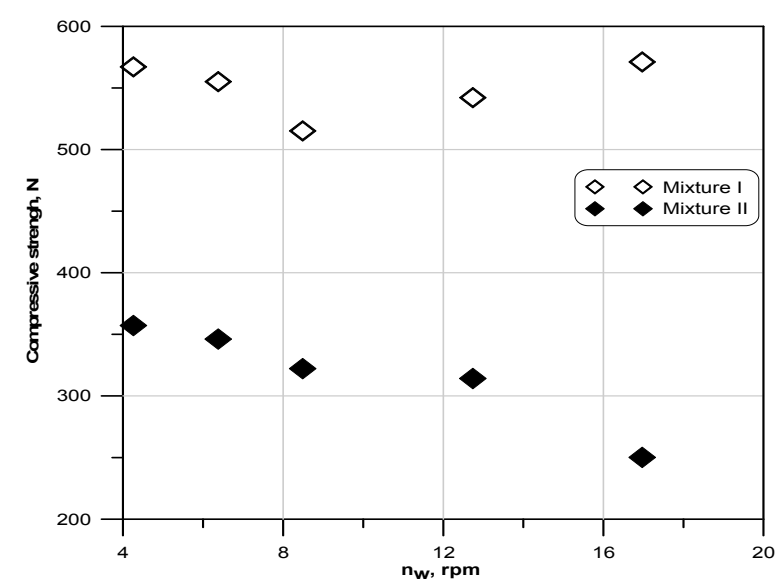

Figure 4. Compressive strength via rotational speed of rollers.

It should be taken into consideration that value of rotational speed of rollers did not cause major changes 
in briquettes parameters. With increase of rotational speed, strength parameters of briquettes slightly fell. It may suggest that strength parameters are determined by chemical binding rather than physical interactions.

Power consumed during briquetting process $N_{\mathrm{b}}$ was determined by the relation:

$$
N_{\mathrm{b}}=2 \cdot\left(M_{\mathrm{t}} \cdot n_{\mathrm{w}}\right) / 9.55, \mathrm{~kW}
$$

where: $M_{\mathrm{t}}$ - torque moment on a roll press, $\mathrm{kNm}$; $n_{\mathrm{w}}$ - roll press rotational speed, rpm.

Mass performance of roll press equipped with saddleshaped forming cavity rings $W_{\mathrm{b}}$ was determined by the relation:

$$
W_{\mathrm{b}}=60 \cdot V_{\mathrm{b}} i_{\mathrm{b}} n_{\mathrm{w}} \rho_{\mathrm{b}}, \mathrm{Mg} / \mathrm{h},
$$

where: $V_{\mathrm{b}}$ - briquette volume, $\mathrm{m}^{3} ; i_{\mathrm{b}}$ - cavities quantity, $i_{\mathrm{b}}=90 ; n_{\mathrm{w}}$ - roll press rotational speed, rpm; $\rho_{\mathrm{b}}$ - briquette density, $\mathrm{Mg} / \mathrm{m}^{3}$.

The density of briquette is one of the most important parameter in such processes. High-density briquette are desirable in terms of transportation, storage and handling. Those technological parameters bring economic benefits. The values of density of studied briquettes are in the ranges $1,30 \div 1,41 \mathrm{~g} / \mathrm{cm}^{3}$ for mixture I and 1,28 $\div 1,35 \mathrm{~g} / \mathrm{cm}^{3}$ for mixture II. Dependence of briquette density via rotational speed of rollers is presented in Fig. 5.

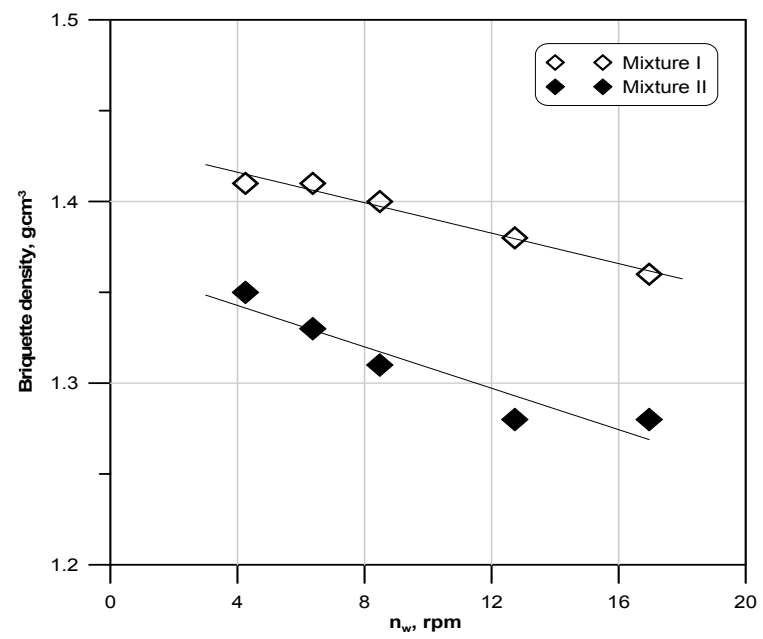

Figure 5. Briquette density in relation to rotational speed of rollers.

Unit energy demand of briquetting process $\left(Z_{\mathrm{e}}\right)$ was determined by the equation:

$$
Z_{b}=N_{b} / W_{b}, \mathrm{kWh} / \mathrm{Mg},
$$

where: $N_{\mathrm{b}}$ - power consumed during briquetting process, $\mathrm{kW} ; W_{\mathrm{b}}$ - mass yield of the roll press, $\mathrm{Mg} / \mathrm{h}$.

Fig. 6 shows influence of unit energy demand unitary versus rotational speed of rollers during briquetting process.

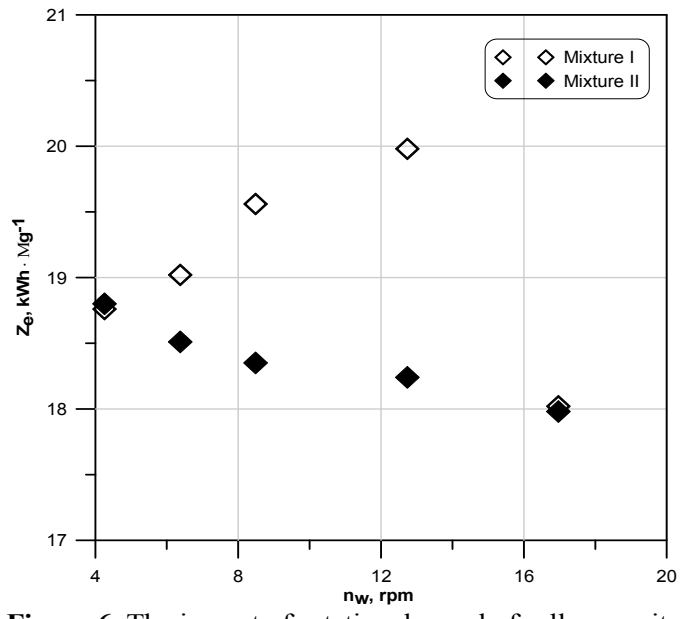

Figure 6. The impact of rotational speed of rolls on unit energy demand during briquetting process.

In this study, the obtained briquettes achieved proper physical parameters such as density, drop and comprehensive strength. The briquettes of sewage sludge and additions in volume $6,5 \mathrm{~cm}^{3}$ were characterised the following parameters:

- compressive strength $\left(D_{168}\right)$ after $168 \mathrm{~h}$ in the range $250 \div 585 \mathrm{~N}$

- direct drop strength, $\mathrm{K}_{0}=98,2 \div 99,6 \%$,

- drop strength after $168 \mathrm{~h}, \mathrm{~K}_{168}=90,2 \div 98,2 \%$,

- briquette density, $\rho_{\mathrm{b}}=1,28 \div 1,41 \mathrm{~g} / \mathrm{cm}^{3}$,

- unit energy demand, $Z_{b}=17,98 \div 19,98 \mathrm{kWh} / \mathrm{Mg}$.

The results indicated that the increase of coal amount in mixture and the increase of rotational speed of rollers make loss of briquette strength parameters. The addition of coal to mixture dose not change unit energy demand of briquetting process.

Combustion of sewage sludge especially in the mixture with coal can be attractive option for thermal utilization of sewage sludge. The comparison of combustion process for sewage sludge and mixture I is shown in Fig. 7.

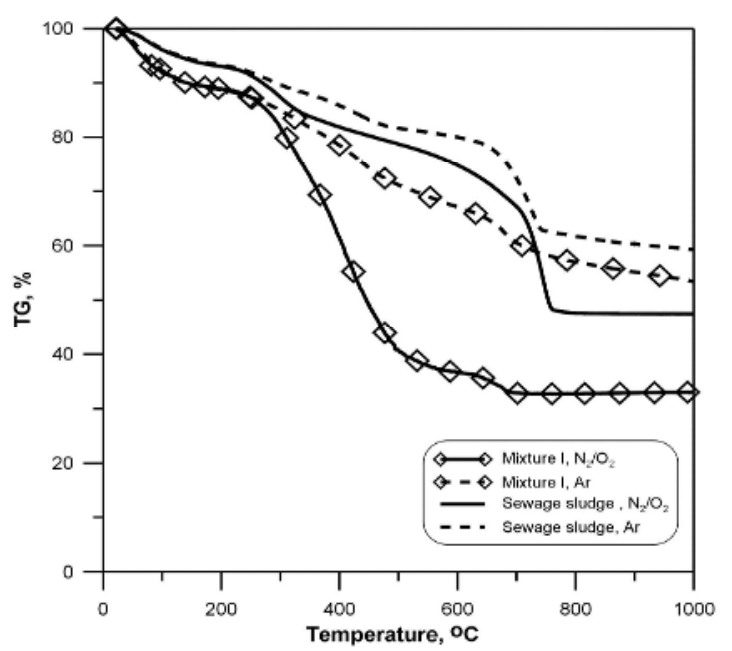

Figure 7. TG curves for mixture I and sewage sludge at $10^{\circ} \mathrm{C} / \mathrm{min}$ in air. 
This figure shows the TG profiles for mixture I and sewage sludge at $10{ }^{\circ} \mathrm{C} / \mathrm{min}$ heating rate at temperatures up to $1000{ }^{\circ} \mathrm{C}$ under air atmosphere. On raising temperature, combustion of studied samples takes place with associated weight loss. The differences between the TG profiles of mixture I and sewage sludge are obvious because of organic and inorganic matter characteristics of the samples. Generally in both cases, they can be divided into three different stages. For the temperature below $300{ }^{\circ} \mathrm{C}$ the slight decay of the tested samples weight are due to the drying process and the release of some light volatiles. The weight loss of the studied samples are about $10 \%$. In the second stage $\left(300{ }^{\circ} \mathrm{C} \div 700{ }^{\circ} \mathrm{C}\right)$ a significant drop in weight of mixture $\mathrm{I}$ is observed caused by the thermal decomposition. Once the temperature is higher than $700{ }^{\circ} \mathrm{C}$ weight loss is not significant. For sewage sludge the thermal conversion takes place about to $800^{\circ} \mathrm{C}$. Fig. 7 presents the comparison between combustion $\left(\mathrm{N}_{2} / \mathrm{O}_{2}\right)$ and pyrolysis (Ar) processes, too. Pyrolysis is the process of thermal decomposition of organic substances in an inert atmosphere. For sewage sludge, pyrolysis process is very complicated because of a wide variety of components. The pyrolysis process of sewage sludge has similar TG curve profile to combustion, and ends before $800{ }^{\circ} \mathrm{C}$. The thermal decomposition is $50 \%$ of total mass at $800{ }^{\circ} \mathrm{C}$ for combustion, but for pyrolysis is less than $40 \%$ of total conversion. In the case of mixture I TG curves have not the same profile. The most abundant release of volatile matter during combustion is observed in the temperature range $200 \div 500{ }^{\circ} \mathrm{C}$. The weight loss in the this step is about $60 \%$. At final combustion temperature $\left(1000{ }^{\circ} \mathrm{C}\right)$, the residue is nearly $30 \%$. The pyrolysis process for mixture I takes place in different temperature ranges and the rate of thermal decomposition is other. The main stage of thermal decomposition occurs to $700{ }^{\circ} \mathrm{C}$. Higher up $700{ }^{\circ} \mathrm{C}$, the small mass loss takes place, too.

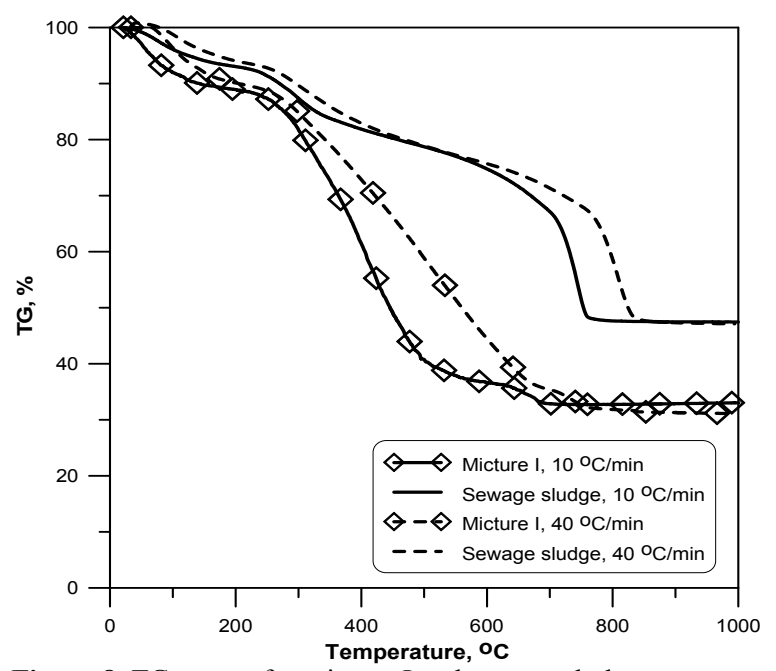

Figure 8. TG curves for mixture I and sewage sludge 10 and 40 and $100{ }^{\circ} \mathrm{C} / \mathrm{min}$ in air.

It may be conclude that amount of final residue depends on kind of thermal decomposition atmosphere as well as chemical composition of sewage sludge and the addition of coal to blend.

Fig. 8 shows the influence of heating rate $\left(10^{\circ} \mathrm{C} / \mathrm{min}\right.$ and $40{ }^{\circ} \mathrm{C} / \mathrm{min}$ ) on TG profiles of mixture I and sewage sludge in the air atmosphere.

As we can observe the increase in heating rate does not cause the change in profile curves. The increase of heating rate cause the shift of combustion curve towards higher temperatures. Combustion of sewage sludge and coal briquettes is more efficient than combustion of sewage sludge without and addition, because process can begin in lower temperature range and amount of ash is lower.

Amount of electricity or heat produced by combustion of sewage sludge and coal briquettes $E_{\mathrm{SSC}}$ can be calculated by using following formula:

$$
E_{\mathrm{SSC}}=m_{\mathrm{C}} W_{\mathrm{C}}+m_{\mathrm{SS}} W_{\mathrm{SS}}-E_{\mathrm{Z}}-E_{\mathrm{t}}-3,6 m_{\mathrm{b}} Z_{\mathrm{e}}, \mathrm{MJ}
$$

where: $m_{\mathrm{C}}-$ mass of coal, $\mathrm{Mg} ; W_{\mathrm{C}}-$ lower heating value of coal, $\mathrm{MJ} / \mathrm{Mg} ; m_{\mathrm{SS}}$ - mass of sewage sludge, $\mathrm{Mg} ; W_{S S}$ - lower heating value of sewage sludge, $\mathrm{MJ} / \mathrm{Mg}$; $E_{\mathrm{Z}}$ - electric or heat energy for dewatering process, $\mathrm{MJ}$; $E_{\mathrm{t}}$ - electric energy for preparing of mixture to unite the briquette, $\mathrm{MJ} ; m_{\mathrm{b}}$ - mass of briquetting material, $\mathrm{Mg}$; $Z_{\mathrm{e}}$ - unit energy demand for briquetting process, $\mathrm{kWh} / \mathrm{Mg}$.

\section{Conclusion}

Accession of Poland to European Union caused numerous changes in waste management. Those changes influenced renewable energy sector [11]. Solutions that helped competitiveness and forced betterment of economical effectiveness (National Plan of Operation in Range of Energy from Renewable Sources, 2010) were introduced. Despite growing significance of ecological methods in municipal sewage sludge in Poland until 2014, huge part of this waste is still being lodged in dumps. In order to counter this process Polish government takes administrative steps which are going to force a discontinuance of this process. One of the main ways to counteract is constant growth of taxes based on environmental harmfulness and dump storage. In addition tax rate depends strongly on moisture of sewage.

The obtained results show possibility of briquetting sewage sludge with waste burnt lime and coal in technological roll press with gravity fed system, equipped with a saddle-shaped cavity forming rings. Usage of this technology can be considered reasonable in wastewater treatment plants localized near agglomerations with at least 100000 citizens, in other words, where building of special incineration plants is uneconomic. According to National Programme for Municipal Sewage Treatment in $2015 \quad 42 \%$ of mentioned waste will be produced in those agglomeration in Poland. Sewage sludge briquetting allows for easier transport to the utilization place and addition of waste burnt lime gives opportunity of combustion in cement kilns. This kind of sewage sludge utilization, not only reduces usage of natural 
resources, but also lowers amount of waste, considered hazardous of the environment in their raw state, thus protects natural environment. Obtained results such as calorific value of sewage sludge and unit energy demand of briquetting process can useful during planning of design municipal power plant.

\section{Acknowledgements}

This article has been prepared within the scope of statutory activity, Contract No. 11.11.130.957.

\section{References}

1. Statistical Yearbook of the Republic of Poland, Warsaw 2012, 104.

2. National plan of operation in range of energy from renewable sources, Warsaw 2010, 127.

3. B. Kosturkiewicz, B. Tora, Waste Forum, 4, 385-388, (2010)

4. A. Magdziarz, M. Wilk, B. Kosturkiewicz, Chem. Proc. Eng., 32, 299-309, (2011)

5. A. Magdziarz, M. Wilk, Energy Conversion Manage., 75, 425-430, (2013)

6. Resolution no. 217 issued by the Council of Ministers on December 24, 2010, on "National wastes management plan 2014", Official Journal Monitor Polski, 101, 1183, 2010.

7. L.I. Darvell, J.M. Jones, B. Gudka, X.C. Baxter, A. Saddawi, A. Williams, A. Malmgren, Fuel, 89, 2881-2890, (2010)

8. A. Skreiberg, O. Skreberg, J. Sandquist, L. Sorum, Fuel, 90, 2189-2197, (2011)

9. D. Vamvuka, E. Karouki, S. Sfakiotakis, Fuel, 90, 1120-1127, (2011)

10. A. Magdziarz, S. Werle, Waste Manage. 34, 174-179, (2014).

11. R. Machnik, B. Karwat, M. Nocuń, J. Niedźwiedzki, Przem. Chem., 94(9), 1530-1533, (2015). 